\title{
Transforming a Compact Disk into a Simple and Cheap Photocatalytic Nanoreactor
}

\author{
Jordi Sans, ${ }^{\dagger, \ddagger}$ Lluís Soler, ${ }^{\dagger,}$ Montserrat Domínguez, ${ }^{\dagger}$ and Jordi Llorca $*, \dagger, \$$ \\ ${ }^{\dagger}$ Institute of Energy Technologies and Barcelona Research Center in Multiscale Science and Engineering and ${ }^{\ddagger}$ Department of \\ Chemical Engineering, Universitat Politècnica de Catalunya, EEBE, Eduard Maristany 16, 08019 Barcelona, Spain
}

\section{Supporting Information}

ABSTRACT: A commercial compact disk has been converted into an effective photocatalytic nanoreactor by depositing a catalyst layer inside the nanochannels by means of an electrophoretic method. The resultant device has been tested for water splitting, obtaining a high yield of hydrogen at an unbeatable low cost.

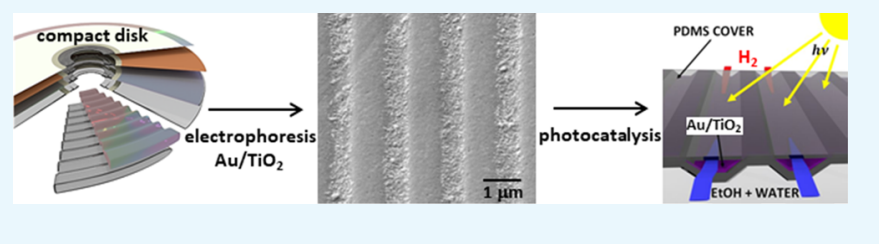

\section{INTRODUCTION}

The nanoreactor concept is usually restricted to hollow structures or cavities with a proper geometry to accommodate reactant molecules in a way that the selectivity of the reaction is strongly enhanced. ${ }^{1,2}$ These confined reaction spaces are found abundantly in biological systems and in several mesoporous artificial structures but they are difficult to engineer for practical application. Microreaction technologies using microfluidic devices, where a thin catalyst layer is fixed onto the walls of micron-sized channels where the reactants flow, have become popular and have demonstrated their excellence in handling a variety of chemical transformations. ${ }^{3,4}$ The increase of surface-to-volume ratio and the decrease of linear dimensions improve dramatically the mass and heat transfer and as a result the overall efficiency of the process is strongly enhanced and the process is much better controlled. In the last decade, the fabrication of miniaturized optofluidic platforms, which combine microfluidics and optics, has emerged as a promising field to boost photocatalytic reactions due to short light travel distance within the microchannels and improved mass and photon transfer. ${ }^{5} \mathrm{~A}$ wide range of mechanical, optical, and etching technologies can be used to manufacture microreactors containing thousands of microchannels in a variety of designs; but with the technologies available nowadays it is difficult to prepare channels with widths below a few microns and when this is possible, the processes involved are terribly laborious and expensive. ${ }^{6-8}$ Here, we demonstrate the way to convert the channels of commercial compact disks (CD) into effective nanoreactors. In this work, we have deposited a uniform layer of $\mathrm{Au} / \mathrm{TiO}_{2}$ catalyst inside the nanochannels of a $\mathrm{CD}$, which measure ca. $200 \mathrm{~nm}$ depth $\times 800 \mathrm{~nm}$ width. We have sealed the nanochannels with a simple silicone film and have tested their performance in the photocatalytic generation of hydrogen. The yield of hydrogen obtained is higher than that reported in other photoreactors and the cost is much lower.

\section{RESULTS AND DISCUSSION}

First, the commercial $\mathrm{CD}$ was delaminated with ethanol to remove the artwork and lacquer external layers and access the assemblage of the polycarbonate matrix containing the nanochannels (Figures $1 \mathrm{~A}$ and S1) and the thin metal layer on top of it. We did not remove the metal layer because, as will be discussed below, this plays a key role for the deposition of the catalyst and it is advantageous for the photocatalytic experiment. In our case, the metal layer was metallic silver with a thickness of about $80 \mathrm{~nm}$ (Figures 1C and S2). The dimensions of the channels were determined by interferometry and scanning electron microscopy (SEM)-focused ion beam (FIB) and are about $200 \mathrm{~nm}$ depth $\times 800 \mathrm{~nm}$ width (Figure $1 \mathrm{~B}, \mathrm{C})$. The $\mathrm{CD}$ was cut into pieces of $2 \mathrm{~cm}$ length $\times 2.5 \mathrm{~cm}$ width with the nanochannels (about 6250 channels per $\mathrm{cm}$ ) aligned along the length.

The $\mathrm{Au} / \mathrm{TiO}_{2}$ photocatalyst used in this work was prepared separately by impregnating preformed $\mathrm{Au}$ nanoparticles (3-4 $\mathrm{nm}$ in diameter, Figure 2A) onto Degussa P90 titania (Au $1 \mathrm{wt}$ $\%)$, followed by calcination at $673 \mathrm{~K}$ to ensure a good contact between the $\mathrm{Au}$ nanoparticles and the $\mathrm{TiO}_{2}$ support. ${ }^{9}$ This photocatalyst was selected because it has been already fully characterized and used in the photogeneration of hydrogen by us, so it represents the perfect choice for a proper comparison between the hydrogen production rate obtained in the nanochannels of the $\mathrm{CD}$ with respect to previous values obtained in other photoreactor configurations. ${ }^{10,11}$ The X-ray diffraction pattern of the photocatalyst (Figure 2B) shows the characteristic peaks of $\mathrm{TiO}_{2}$ and broad peaks at 38.2 and $44.4^{\circ}$ corresponding to the $\mathrm{Au}$ nanoparticles. As expected, after deposition and calcination, the Au nanoparticles are metallic, as deduced from the X-ray photoelectron spectrum shown in Figure 2C, corresponding to the $\mathrm{Au} 4 \mathrm{f}$ core level (peak of $\mathrm{Au}$ $4 \mathrm{f}_{7 / 2}$ at $\left.84.0 \mathrm{eV}\right){ }^{9}$ Figure $2 \mathrm{D}$ corresponds to a representative

Received: April 18, 2018

Accepted: June 11, 2018

Published: June 27, 2018 


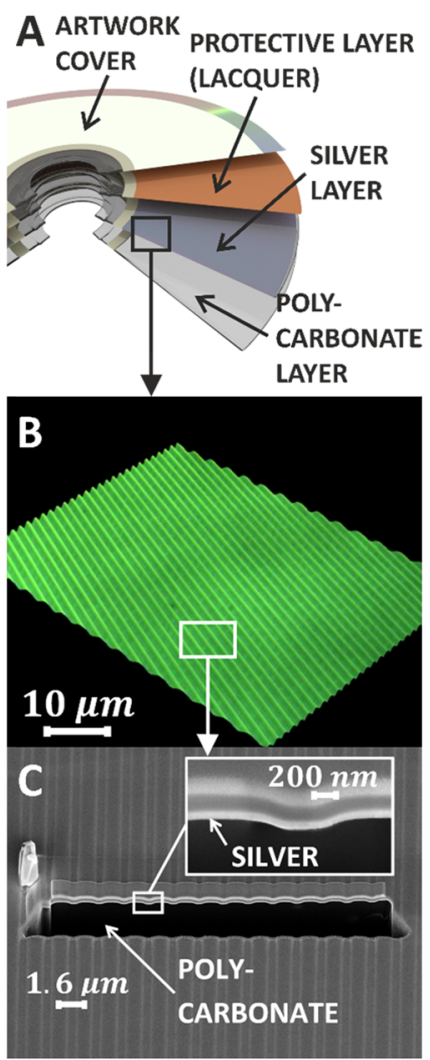

Figure 1. (A) Scheme of the different layers in a commercial CD. (B) Interferometry image of the nanochannels of the $\mathrm{CD}$ after removing the artwork and lacquer external layers. (C) SEM image of the nanochannels and FIB cut showing the Ag metal layer.

high-resolution transmission electron microscopy (HRTEM) image of the $\mathrm{Au} / \mathrm{TiO}_{2}$ photocatalyst, showing a good contact between an Au nanoparticle and the titania support.

Several methods were attempted to deposit the $\mathrm{Au} / \mathrm{TiO}_{2}$ catalyst particles on the nanochannels to attain a uniform layer without blocking the nanochannels. Casting and spin-coating proved to be inadequate because aggregates of catalyst particles were abundant and randomly distributed over the nanochannels, whatever the physical-chemical properties of the solvent used (Figures S3 and S4). In contrast, electrophoresis allowed obtaining a homogeneous layer of catalyst particles perfectly distributed over the nanochannels, which, remarkably, were deposited exclusively inside the channels (Figure 3). This is of great importance for the subsequent sealing of the nanochannels in the nanoreactor. Electrophoresis was possible, thanks to the presence of the thin metal layer over the polycarbonate structure of the $\mathrm{CD}$. The best conditions for the electrophoretic deposition were $0.8 \mathrm{~V}$ at a working distance of $6 \mathrm{~cm}$ for $1 \mathrm{~min}$ from an aqueous suspension of catalyst of $5 \mathrm{mg}$ $\mathrm{mL}^{-1}$ at $\mathrm{pH}=13(\mathrm{KOH})$. Under these conditions, $1.2 \mu \mathrm{g}_{\mathrm{cat}}$ $\mathrm{cm}^{-2}$ was deposited with excellent reproducibility. Taking into account that the electrophoretic field is stronger at the corners delimited by the nanochannels and that the pitch distance of the nanochannels doubles that of the width of the nanochannels (ca. $1.6 \mu \mathrm{m}$ vs $800 \mathrm{~nm}$, Figure 1C), the charged catalyst particles are likely directed toward the interior of the nanochannels during electrophoresis, allowing for a selective deposition of the catalyst only on the walls of the nanochannels. Following electrophoresis, the nanochannels were gently rinsed with ethanol and dried under Ar at room temperature. A transparent cover of silicone film was prepared separately from poly(dimethylsiloxane) (PDMS) and bonded to the $C D$ pieces with functionalized nanochannels by applying an air plasma activation treatment, as described elsewhere. ${ }^{10}$ Microfluidic inlet and outlet connections were inserted perpendicular to the nanochannels, which, according to fluid simulations (Figure S5), ensured a homogeneous velocity distribution.

The photocatalytic tests were performed at room temperature in gas phase and in continuous mode by introducing $\mathrm{Ar}$ saturated with water and ethanol $\left(\mathrm{H}_{2} \mathrm{O} / \mathrm{EtOH}=90: 10\right.$ molar basis, $\mathrm{GHSV}=5.6 \times 10^{6} \mathrm{~h}^{-1}, \mathrm{~W} / \mathrm{F}=0.013 \mathrm{mg}_{\text {cat }} \mathrm{min} \mathrm{mL}^{-1}$ ) into the nanoreactor. Ethanol was used as sacrificial agent to enhance the lifetime of the electron-hole pairs generated in the $\mathrm{TiO}_{2}$ semiconductor upon light irradiation. ${ }^{12}$ A complete explanation of the physicochemical process taking place over $\mathrm{Au} / \mathrm{TiO}_{2}$ for the photogeneration of hydrogen from waterethanol can be found in the literature. ${ }^{12}$ The outlet of the nanoreactor was sampled on-line with a gas chromatograph (GC) for the complete analysis of products. The light source was placed perpendicular to the nanoreactor facing the silicone cover (Figure 4A). It is composed of four light-emitting diodes (LEDs) emitting at $365 \pm 5 \mathrm{~nm}$ and a light guide for a homogeneous light distribution. ${ }^{13}$ The light irradiance was measured exactly at the position of the nanoreactor (UV radiation monitor from Solar Light Co.) and was varied between ca. 15 and $75 \mathrm{~mW} \mathrm{~cm}^{-2}$. The only products of the photoreaction detected by GC were hydrogen and acetaldehyde, which originated by the oxidation of ethanol by the holes in the valence band of the photocatalyst. ${ }^{10-12}$

Figure 4B shows the hydrogen production rates obtained at different irradiance values, as calculated from the GC analyses and gas flow used. As expected, the higher the irradiance the higher the hydrogen production rate. A stability test was carried out at $75 \mathrm{~mW} \mathrm{~cm} \mathrm{~cm}^{-2}$ and a remarkable constant hydrogen production rate of $38 \mu \mathrm{mol} \mathrm{H}_{2} \min ^{-1} \mathrm{~g}^{-1}$ was recorded (Figure 4C), which equals to a $\mathrm{H}_{2}$ concentration of $1.3 \times 10^{-3} \%$. These photocatalytic results can be compared straightforward with those obtained in a silicone microreactor containing conventional channels of ca. $500 \mu \mathrm{m}$ width loaded with exactly the same $\mathrm{Au} / \mathrm{TiO}_{2}$ photocatalyst. ${ }^{10}$ Under an irradiance of ca. $24 \mathrm{~mW} \mathrm{~cm}^{-2}$, the hydrogen production rate obtained with the nanoreactor almost doubles that obtained with the conventional microreactor, 29 vs $16 \mu \mathrm{mol} \mathrm{H}_{2} \mathrm{~min}^{-1}$ $\mathrm{g}^{-1}$ (Figure 4B). Taking into account that these are normalized rate values obtained with exactly the same photocatalyst under the same conditions, the increase in the hydrogen production rate observed when the nanoreactor is used can only be explained in terms of better photon delivery and mass transfer, which are both critical in any photocatalytic process. ${ }^{11}$ In the nanoreactor, both the smaller cross section of the channels and the thinner catalyst layer deposited over the nanochannels with respect to the conventional microchannels ( $800 \mathrm{~nm}$ vs $500 \mu \mathrm{m}$ width) favor mass transfer. In addition, the metal layer of the $\mathrm{CD}$ beneath the catalyst layer reflects the photons initially not absorbed and redirect them again through the catalyst enhancing the photocatalytic process due to a better photon usage (Figure 4A).

\section{CONCLUSIONS}

We have reported here a high efficient, easy to manufacture, and low-cost nanoreactor that can be used in a wide range of chemical processes. We have tested a nanoreactor containing a 

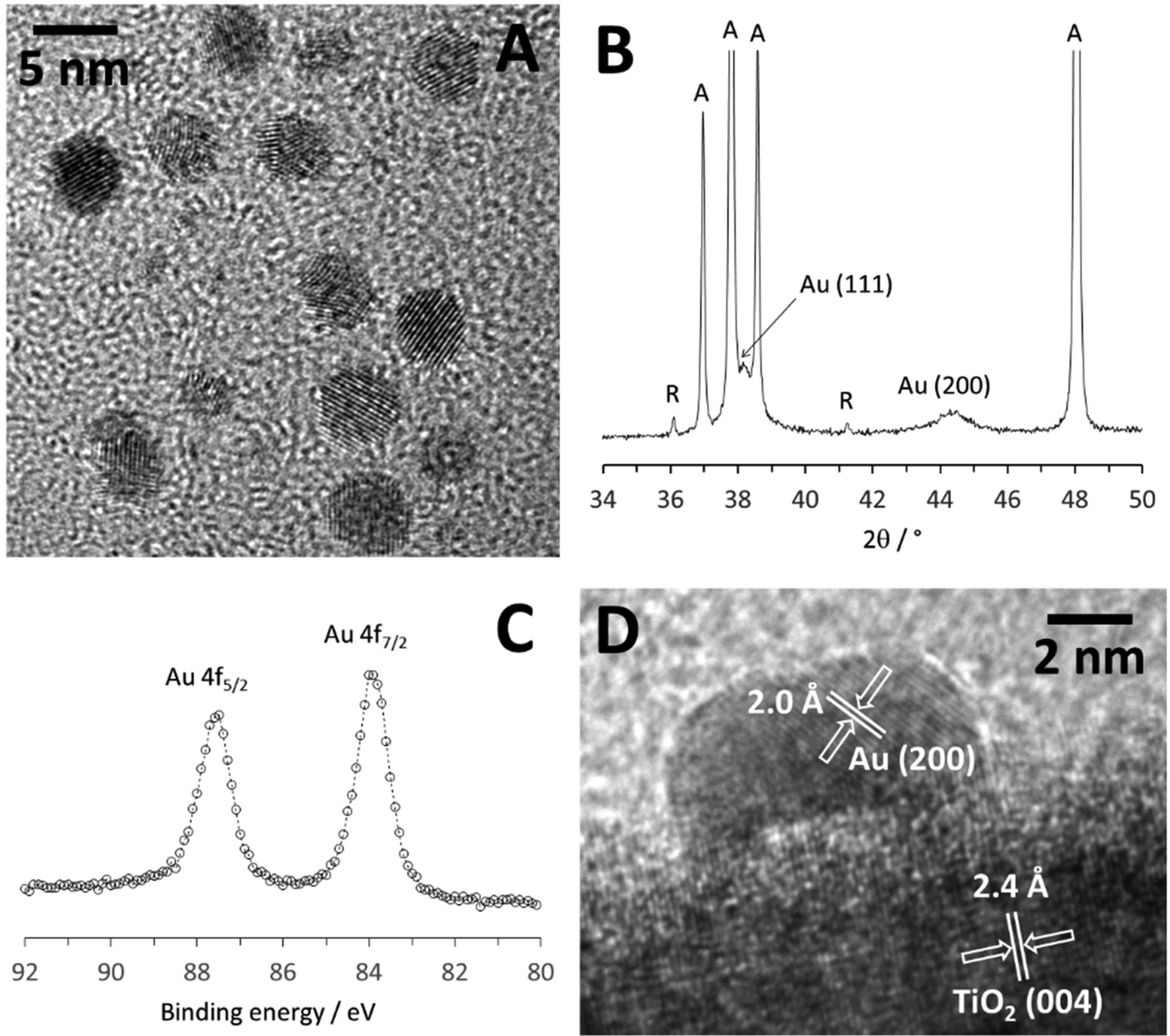

Figure 2. (A) HRTEM image of the preformed Au nanoparticles. (B) Powder X-ray diffraction (XRD) of the $\mathrm{Au} / \mathrm{TiO}_{2}$ photocatalyst; $\mathrm{A}=\mathrm{anatase}$, $\mathrm{B}=$ rutile. (C) $\mathrm{Au} 4 \mathrm{f} \mathrm{XP}$ spectrum of the $\mathrm{Au} / \mathrm{TiO}_{2}$ photocatalyst. (D) HRTEM of the $\mathrm{Au} / \mathrm{TiO}_{2}$ photocatalyst.

standard $\mathrm{Au} / \mathrm{TiO}_{2}$ photocatalyst for water splitting at room temperature (using ethanol as sacrificial agent) and have demonstrated a remarkable performance when compared to conventional microreactors, which is explained in terms of both improved mass transfer and photon delivery. The critical issue of depositing a catalyst layer selectively over the walls of the nanochannels can be accomplished by electrophoresis, provided that parameters such as voltage, time, and $\mathrm{pH}$ are accurately selected. This work offers a simple and low-cost method to fabricate photocatalytic nanoreactors, which could open the door for studying reaction mechanisms and kinetics with novel photocatalysts and obviating the use of expensive and bulky experimental setups that usually require a high quantity of catalytic materials containing precious metals. The reported photocatalytic nanoreactor in this work has the potential to minimize labor force, cost of experiment, and allow for rapid optimization of reactions.

\section{EXPERIMENTAL SECTION}

4.1. Characterization Techniques. Morphological data were obtained using a Veeco WYKO 9300NT using the vertical scanning interferometry mode with a magnification parameter of 100. Scanning electron microscopy (SEM) images were recorded at $5 \mathrm{kV}$ using a Zeiss Neon 40 Crossbeam Station instrument equipped with a field emission source. Cross-sectional images were obtained using a focused ion beam (FIB). Cuts were performed with a Gallium FIB CANION31 operating at $30 \mathrm{kV}$ and $50 \mathrm{pA}$. Fourier-transform infrared spectroscopy spectra were recorded in a Nicolet 6700 spectrometer equipped with a Smart Orbit attenuated total reflection accessory using a germanium crystal. Surface chemical characterization was done by X-ray photoelectron spectroscopy on a SPECS system. The spectrometer was equipped with a XR50 source operating the $\mathrm{Al}$ anode at $150 \mathrm{~W}$ and a Phoibos 150 MCD-9 detector. The pass energy of the hemispherical analyzer was set at $25 \mathrm{eV}$, and the energy step of high-resolution spectra was set at $0.1 \mathrm{eV}$. The pressure in the analysis chamber was always below $10^{-7} \mathrm{~Pa}$, and binding energy values were referred to the $\mathrm{C} 1 \mathrm{~s}$ peak at $284.8 \mathrm{eV}$. Powder X-ray diffraction (XRD) patterns were recorded using a Siemens D5000 diffractometer using $\mathrm{Cu} \mathrm{K} \alpha$ radiation (45 $\mathrm{kV}, 35 \mathrm{~mA}$ ) in Bragg-Brentano geometry. The diffraction patterns were recorded in steps of $0.02^{\circ}$ and $1 \mathrm{~s}$ per step. Highresolution transmission electron microscopy (HRTEM) was carried out with a Jeol J2010F instrument equipped with a field emission electron source operated at $200 \mathrm{kV}$. Sample was prepared by dispersing the catalysts in methanol. A drop of the suspension was then allowed to evaporate on a carbon-coated copper grid.

4.2. Au Nanoparticles Preparation and Photocatalyst Deposition. The preparation of the model Au nanoparticles was reported in detail in ref 9 . They were synthesized following the two-phase method described for the synthesis of dodecanethiol-capped monometallic $\mathrm{Au}$ nanoparticles, ${ }^{14}$ which involved the transfer of $\mathrm{AuCl}_{4}^{-}$to a toluene solution using tetraoctylammonium bromide followed by a single reduction step with $\mathrm{NaBH}_{4}$ in the presence of dodecanethiol. Electrophoresis deposition of the photocatalyst was performed using a customized setup consisting of a Promax FA-665 voltage source, support for electrodes designed for working 


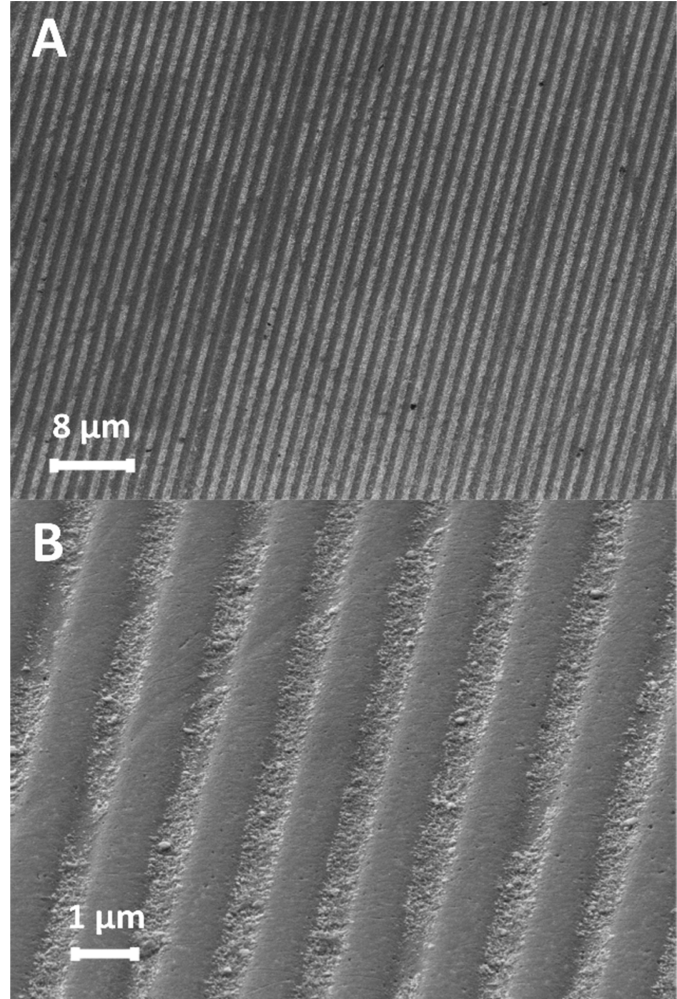

Figure 3. (A, B) SEM images recorded at different magnifications showing a homogeneous $\mathrm{Au} / \mathrm{TiO}_{2}$ catalyst layer inside the nanochannels obtained by electrophoretic deposition $(0.8 \mathrm{~V}, t=1 \mathrm{~min}, \mathrm{pH}$ $=13$ ).

with different distances and with space for a reference electrode in the middle, connected to a LECROY WAVESURFER 24XS oscilloscope. As counter electrode, another CD sample of the same area than the one placed in the working electrode was used.

4.3. Photocatalytic Experiments. Photocatalytic tests were performed at room temperature and atmospheric pressure in the prepared photocatalytic nanoreactor. An argon stream of $4.7 \mathrm{~mL} \mathrm{m^{-1 }}$ was bubbled to a Dreschel bottle containing $\mathrm{EtOH}$ and $\mathrm{H}_{2} \mathrm{O}$ to obtain a gaseous reactant mixture of $\mathrm{EtOH} / \mathrm{H}_{2} \mathrm{O}=1: 9$ (molar basis), which was directly introduced into the nanoreactor. The reactor is built with two tygon tubes, one provided with a gaseous reagents stream inlet and the second one provided with an outlet, which was continuously monitored by a microgas chromatograph (GC) Agilent 490. The GC was equipped with MS $5 \AA$, Plot U, and Stabilwax columns for a complete and continuous analysis of the photoreaction products. The UV light source used to illuminate the photoreactor was purchased from SACOPA, S.A.U. It is composed of four LEDs at $365 \pm 5 \mathrm{~nm}$ and a synthetic quartz glass (UV grade fused silica) cylindrical lens that transmits the light to the photocatalytic nanoreactor.

\section{ACKNOWLEDGMENT}

This work has been funded by MINECO/ERDF project ENE2015-63969-R and GC 2017 SGR 128. J.L. is a Serra Húnter Fellow and is grateful to ICREA Academia program.
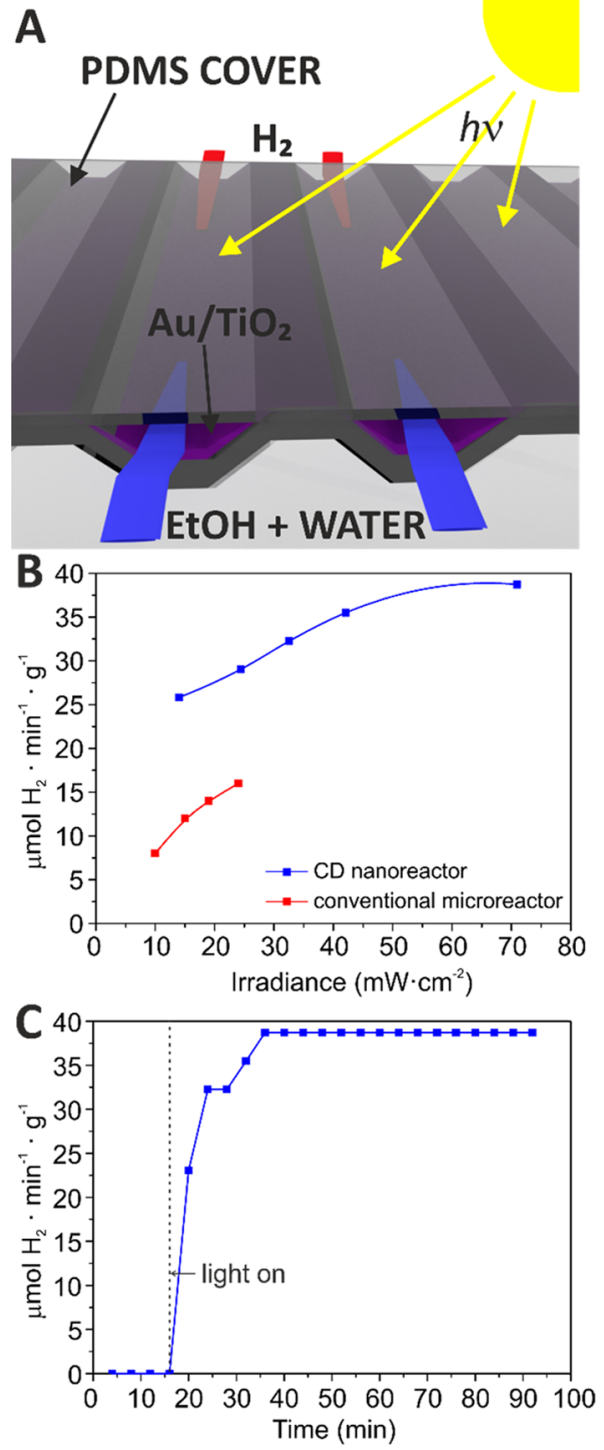

Figure 4. (A) Scheme of the nanoreactor. A mixture of gaseous water and ethanol flows inside the nanochannels of the $\mathrm{CD}$ covered by an $\mathrm{Au} / \mathrm{TiO}_{2}$ catalyst layer; the nanochannels are sealed with a PDMS cover, which allows direct illumination. (B) Normalized hydrogen production rates obtained in the $\mathrm{CD}$ nanoreactor (blue) and in a conventional microreactor (red, data from ref 10). (C) Stability test conducted over the $\mathrm{CD}$ nanoreactor under ca. $75 \mathrm{~mW} \mathrm{~cm} \mathrm{~mW}^{-2}$.

\section{ASSOCIATED CONTENT}

\section{Supporting Information}

The Supporting Information is available free of charge on the ACS Publications website at DOI: 10.1021/acsomega.8b00739.

IR spectrum of the polycarbonate matrix of the compact disk; Auger spectrum of the Ag layer of the compact disk; SEM images of the nanochannels after deposition of photocatalyst by casting and spin-coating methods; fluid simulations for velocity distribution at the entrance of the nanochannels (PDF)

\section{AUTHOR INFORMATION}

\section{Corresponding Author}

*E-mail: jordi.llorca@upc.edu. 


\section{ORCID $\odot$}

Lluís Soler: 0000-0003-1591-3366

Jordi Llorca: 0000-0002-7447-9582

Notes

The authors declare no competing financial interest.

\section{REFERENCES}

(1) Vriezema, D. M.; Aragonès, M. C.; Elemans, J. A. A. W.; Cornelissen, J. J. L. M.; Rowan, A. E.; Nolte, R. J. M. Self-assembled nanoreactors. Chem. Rev. 2005, 105, 1445-1489.

(2) Renggli, K.; Baumann, P.; Langowska, K.; Onaca, O.; Bruns, N.; Meier, W. Selective and responsive nanoreactors. Adv. Funct. Mater. 2011, 21, 1241-1259.

(3) Mason, B. P.; Price, K. E.; Steinbacher, J. L.; Bogdan, A. R.; McQuade, T. D. Greener approaches to organic synthesis using microreactor technology. Chem. Rev. 2007, 107, 2300-2318.

(4) Roberge, D. M.; Zimmermann, B.; Rainone, F.; Gottsponer, M.; Eyholzer, M.; Kockmann, N. Microreactor Technology and Continuous Processes in the Fine Chemical and Pharmaceutical Industry: Is the Revolution Underway? Org. Process Res. Dev. 2008, 12, 905-910.

(5) Parmar, J.; Jang, S.; Soler, L.; Kim, D.-P.; Sánchez, S. Nanophotocatalysts in microfluidics, energy conversion and environmental applications. Lab Chip 2015, 15, 2352-2356.

(6) Ehrfeld, W.; Hessel, V.; Lowe, H. Microreactors: New Technology for Modern Chemistry; Wiley-VCH Verlag GmbH: Weinheim, Germany, 2000.

(7) Llorca, J.; Casanovas, A.; Trifonov, T.; Rodríguez, A.; Alcubilla, R. First use of macroporous silicon loaded with catalyst film for a chemical reaction: A microreformer for producing hydrogen from ethanol steam reforming. J. Catal. 2008, 255, 228-233.

(8) Divins, N. J.; López, E.; Rodríguez, Á; Vega, D.; Llorca, J. Bioethanol steam reforming and autothermal reforming in 3- $\mu \mathrm{m}$ channels coated with $\mathrm{RhPd} / \mathrm{CeO}_{2}$ for hydrogen generation. Chem. Eng. Process.: Process Intensif. 2013, 64, 31-37.

(9) Llorca, J.; Domínguez, M.; Ledesma, C.; Chimentao, R.; Medina, F.; Sueiras, J.; Angurell, I.; Seco, M.; Rossell, O. Propene epoxidation over $\mathrm{TiO}_{2}$-supported $\mathrm{Au}-\mathrm{Cu}$ alloy catalysts prepared from thiolcapped nanoparticles. J. Catal. 2008, 258, 187-198.

(10) Castedo, A.; Uriz, I.; Soler, L.; Gandía, L. M.; Llorca, J. Kinetic analysis and CFD simulations of the photocatalytic production of hydrogen in silicone microreactors from water-ethanol mixtures. Appl. Catal., B 2017, 203, 210-217.

(11) Taboada, E.; Angurell, I.; Llorca, J. Dynamic photocatalytic hydrogen production from ethanol-water mixtures in an optical fiber honeycomb reactor loaded with $\mathrm{Au} / \mathrm{TiO}_{2}$. J. Catal. 2014, 309, 460467.

(12) Murdoch, M.; Waterhouse, G. I. N.; Nadeem, M. A.; Metson, J. B.; Keane, M. A.; Howe, R. F.; Llorca, J.; Idriss, H. The effect of gold loading and particle size on photocatalytic hydrogen production from ethanol over $\mathrm{Au} / \mathrm{TiO}_{2}$ nanoparticles. Nat. Chem. 2011, 3, 489-492.

(13) Aguiló, E.; Soler, L.; Casanovas, A.; Moro, A. J.; Lima, J. C.; Rodríguez, L.; Llorca, J. Gold(I)-Complex-Titania Hybrid Photocatalyst for Hydrogen Production. ChemCatChem 2017, 9, 32893292.

(14) Brust, M.; Walker, M.; Bethell, D.; Schiffrin, D. J.; Whyman, R. Synthesis of thiol-derivatised gold nanoparticles in a two-phase liquid-liquid system. J. Chem. Soc., Chem. Commun. 1994, 801-802. 